Journal of Engineering and Applied Sciences 14 (20): 7557-7565, 2019

ISSN: 1816-949X

(C) Medwell Journals, 2019

\title{
Computerized Representation of Noncircular Gear Centrodes and Teeth Generation using Double Circular Arc Profile
}

\author{
Mansoor Ali Ismail and Mohammad Qasim Abdullah \\ Department of Mechanic, College of Engineering, University of Baghdad, Baghdad, Iraq
}

\begin{abstract}
This study covers the method of representation of any pitch curve (centrode shape) in noncircular gears by deriving a general mathematical equation contains a number of parameters such that this equation can give any centrode shape depending on the selected values of these parameters. In addition, a tooth of double circular arc profile has been generated by hob method and distributed over the pitch curve of noncircular gear by using the required equations of tooth profile generation. These equations are applicable for any module and pressure angle and give the required double circular arc tooth form. Equations of pitch curve representation and tooth profile generation have been programmed using SOLIDWORK program. Therefore, when the parameters of pitch curve and tooth profile have been changed, the program will generate the required shape of noncircular gear centrode and the tooth form which can be distributed over the pitch curve. The resulting noncircular gear can be manufactured by CNC machine by coupling SOLDWORK program file of the generated noncircular gear with this machine. Also, static and dynamic analysis of these gears can be achieved using SOLIDWORK package or using any other program accept SOLIDWORK files such as ANSYS package.
\end{abstract}

Key words: Noncircular gears, computerized representation of gears, centrodes of noncircular gear, gears, gears generation, pitch curve representation

\section{INTRODUCTION}

Non-circular gears have a number of important applications in several fields such as that in artificial heart, pressing machine, gear pump, mechanism of linkage for velocity or displacement function. Study the behavior of noncircular gear drive under working conditions needs to represent the gear shape accurately with different gear design parameters. This enables to analyze the behavior of noncircular gears using any theoretical or experimental test method. Thus, it is important to cover the mathematical relations of noncircular gear centrodes and teeth generation to represent the noncircular gear in $3 \mathrm{D}$ space. By Cunningham (1959) presented a design method for variable radius (non-circular) gears that can be used as a function generator. By Kuczewski (1988) introduced a method to determine the centrode pitch curve in non-circular gears of elliptical type. By Danieli (2000) suggested a method to find the teeth profile in non-circular gears of constant pressure angle. By this method, non-circular gears of special shapes can be generated by using milling machine that is controlled numerically. By Bair (2002) introduced a mathematical model to represent the noncircular gear of elliptic type that has a rotational axis coincides with the ellipse geometrical center. Shaper cutter has been used to manufacture this gear. Mundo and Danieli (2004) proposed a new method for noncircular gear design. The main idea of the proposed method is to represent the meshing progress of non-circular gears by using appropriate mathematical modelling that leads to derive a suitable differential equation which can be solved by numerical integration and generate the required non-circular gear (Mundo and Danieli, 2004). Li et al. (2007) developed a numerical method to generate tooth profile of non-circular gear with accurate flank. This method allows to replace classical tooth generation method by direct tooth representation method (Li et al., 2007). Litvin et al. (2007) introduced three methods to generate elliptical gears by hob, rack-cutter and shaper with full description and mathematical representation of generation process (Litvin et al., 2007). Riaza et al. (2007) employed non-parametric curves of B-spline and Bezier to represent variable radius gears with $\mathrm{N}$-lobe by propose a suitable method to revolve angular coordinates of pinion and gear using these non-parametric curves. As the displacement law is formulated, pitch curves of pinion and gear can be created analytically (Riaza et al., 2007). By

Corresponding Author: Mansoor Ali Ismail, Department of Mechanic, College of Engineering, University of Baghdad, Baghdad, Iraq 
Liu and Chen (2008) derived the equation of pitch curve in non-circular gear using Fourier series by substituting the speed ratio as a Fourier series. Consequently, angular displacement equation can be evaluated by integration method. Marius and Laurentia (2010) made a literature survey of non-circular gear generation methods based on simulation of generation, theory of enveloping and analytical approximation of tooth profile. Vasie and Andrei (2011) adopted a general method to design centrode shape of variable radius gear using super formula of Gieli which contains a number of design parameters (Marius and Laurentia, 2010). Han et al. (2015) proposed a method to generate the profiles of noncircular gear teeth and derive the required mathematical equations by applying slotting cutter (Han et al., 2015). Vanegas-Useche et al. (2016) developed a new variable radius gear with minimized shaft acceleration. The centrode shape of this gear is depend on maximum acceleration required and centrode smoothness (Vanegas-Useche et al., 2016). Zhang and Fan (2018) suggested a new mathematical model of variable radius gear with small rotational inertia. The formulation of this model is based on kinematic and calculus principles (Zhang and Fan, 2018). Zheng et al. (2018) introduced a new approach for generation of variable radius gears by a face milling that used in generation process of spiral-bevel gear (Zheng et al., 2018).

The review above shows the important and difficulty of noncircular gear generation and representation. Therefore, this study will cover teeth generation method and pitch curve representation in noncircular gears using different mathematical relations and coordinate transformations.

\section{MATERIALS AND METHODS}

Derivation of noncircular gear centrodes: The first and the most important step in the design of noncircular gears is to derive the centrodes of these gears in this case, we apply the following:

- Suppose two movable coordinate systems $\mathrm{S}_{1}\left(\mathrm{x}_{1}, \mathrm{y}_{1}\right)$ and $\mathrm{S}_{2}\left(\mathrm{x}_{2}, \mathrm{y}_{2}\right)$ which are rigidly connected to gear 1 and pinion 2 , respectively.

- Consider a fixed coordinate system $\mathrm{S}_{\mathrm{f}}\left(\mathrm{x}_{\mathfrak{f}} \mathrm{y}_{\mathrm{f}}\right)$ which are rigidly connected to the gear drive frame as shown in Fig. 1.

While the rotation process of noncircular gears continues, the instantaneous center of rotation (I) moves along center distance $\mathrm{C}$. Thus, the traced out path by the instantaneous center of rotation in $\mathrm{S}_{\mathrm{f}}$ coordinate system can be represented by the straight line $\mathrm{r}_{\mathrm{f}}(\mathrm{u})$ where, $\mathrm{u}=\overline{\mid \mathrm{q}} \mathrm{I} \mid$.

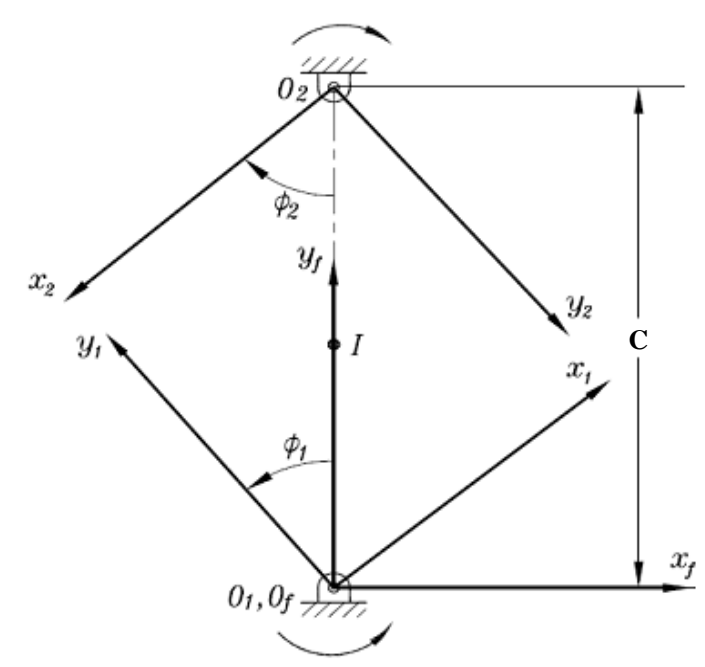

Fig. 1: Noncircular gear centrode of fixed coordinate system $\mathrm{S}_{\mathrm{f}}\left(\mathrm{x}_{\mathrm{G}} \mathrm{y}_{\mathrm{f}}\right)$ and movable coordinate systems $\mathrm{S}_{1}\left(\mathrm{x}_{1}, \mathrm{y}_{1}\right), \mathrm{S}_{2}\left(\mathrm{x}_{2}, \mathrm{y}_{2}\right)$

In the same time, the instantaneous center of rotation (I) moves along centrodes $\sigma_{1}$ and $\sigma_{2}$ of gears 1 and 2 in the coordinate systems $\mathrm{S}_{1}$ and $\mathrm{S}_{2}$. Thus, the centrodes can be determined from the path traced out by point (I) as $r_{1}$ and $r_{2}$ in coordinate systems $S_{1}$ and $S_{2}$ (Litvin et al., 2009):

$$
\begin{aligned}
& \mathrm{r}_{1}\left(\mathrm{u}, \varnothing_{1}\right)=\mathrm{M}_{1 \mathrm{f}}\left(\varnothing_{1}\right) \mathrm{r}_{\mathrm{f}}(\mathrm{u}) \\
& \mathrm{r}_{2}\left(\mathrm{u}, \varnothing_{2}\right)=\mathrm{M}_{2 \mathrm{f}}\left(\varnothing_{2}\right) \mathrm{r}_{\mathrm{f}}(\mathrm{u})
\end{aligned}
$$

where, $\mathrm{M}_{\mathrm{j}}(\mathrm{j}=1,2)$ represent the matrices of coordinate transformation from $S_{\mathrm{f}}$ to $S_{\mathrm{j}} \cdot \varnothing_{1}$ and $\varnothing_{2}$ are the rotational angles of gears centrodes. Now, to derive the noncircular gear centrode consider the following cases of the derivation (Litvin and $\mathrm{Lu}, 1997$ ):

Case 1: When the derivative function $\mathrm{m}_{12}\left(\oslash_{1}\right)=\mathrm{d} \varnothing_{1} / \mathrm{d} \varnothing_{2}$ and the center distance of the gear drive (C) are given: first, take in to account that:

$$
\mathrm{m}_{12}\left(\varnothing_{1}\right)=\frac{\mathrm{d} \varnothing_{1}}{\mathrm{~d} \varnothing_{2}}=\frac{\mathrm{r}_{2}}{\mathrm{r}_{1}}=\frac{\mathrm{C}-\mathrm{r}_{1}}{\mathrm{r}_{1}}
$$

Therefore, the following expression for centrode $\sigma_{1}$ can be obtained:

$$
\mathrm{r}_{1}\left(\varnothing_{1}\right)=\frac{\mathrm{C}}{1+\mathrm{m}_{12}\left(\varnothing_{1}\right)}
$$

While the expression for centrode $\sigma_{2}$ is determined as: 


$$
\begin{aligned}
& \mathrm{r}_{2}\left(\varnothing_{1}\right)=\mathrm{C} \frac{\mathrm{m}_{12}\left(\varnothing_{1}\right)}{1+\mathrm{m}_{12}\left(\varnothing_{1}\right)} \\
& \varnothing_{2}\left(\varnothing_{1}\right)=\int_{0}^{\varnothing_{1}} \frac{\mathrm{d} \varnothing_{1}}{\mathrm{~m}_{12}\left(\varnothing_{1}\right)}
\end{aligned}
$$

The function $\mathrm{m}_{12}\left(\varnothing_{1}\right)$ must be a differentiable and positive function. The requirement of positive values of $\mathrm{m}_{12}\left(\varnothing_{1}\right)$ in the area can be observed easily because the gears rotation may be achieved in one direction only as a continued one.

Case 2: When the function $y(x)$ is given such that $\mathrm{x}_{1} \leq \mathrm{x} \leq \mathrm{x}_{2}$. In this case, the rotational angles of the driving and driven gears are proportional to $\mathrm{x}$ and $\mathrm{y}(\mathrm{x})$, respectively. Thus, the following expressions for the scalar coefficients $k_{1}$ and $k_{2}$ are obtained:

$$
\begin{aligned}
& \varnothing_{1}=\mathrm{k}_{1}\left(\mathrm{x}-\mathrm{x}_{1}\right) \\
& \varnothing_{2}=\mathrm{k}_{2}\left(\mathrm{y}(\mathrm{x})-\mathrm{y}\left(\mathrm{x}_{1}\right)\right)
\end{aligned}
$$

The gear ratio is determined as:

$$
\mathrm{m}_{12}(\mathrm{x})=\frac{\mathrm{d} \varnothing_{1}}{\mathrm{~d} \varnothing_{2}}=\frac{\mathrm{k}_{1}}{\mathrm{k}_{2} \mathrm{y}^{\prime}(\mathrm{x})}
$$

It should be observed that the derivative $\mathrm{m}_{12}(\mathrm{x})$ function must be a positive function in the range $x_{1} \leq x \leq x_{2}$.

Condition of closed centrodes: The conditions for obtaining closed curves centrodes are formulated as the following for each driving and driven gear separately.

Centrode $\sigma_{1}$ : Recall that this centrode is $r_{1}\left(\theta_{1}\right),\left(\theta_{1}=\oslash_{1}\right)$ is represented by Eq. 4. From this equation, it is clear that driving centrode $\sigma_{1}$ can be obtained as a closed form curve, if the derivative function $\mathrm{m}_{12}\left(\varnothing_{1}\right)$ is a periodic function with period $T=T_{1} / n_{1}$ where, $T_{1}$ is the period of revolution for gear 1 and $n_{1}$ is an integer number.

Centrode $\sigma_{2}$ : This centrode is obtained by Eq. 5 for $r_{2}\left(\varnothing_{1}\right)$ and $\varnothing_{2}\left(\varnothing_{1}\right)$ which form a closed curve, if the function $\mathrm{m}_{12}\left(\varnothing_{1}\right)$ is a periodic function with period $\mathrm{T}=\mathrm{T}_{1} / \mathrm{n}_{1}$ as in centrode $\sigma_{1}$. This is mean that the interval of variation of $\varnothing_{1}$ during one revolution is a multiple of $2 \pi / n_{1}$. Finally, the following conditions must be applicable: the ratio between revolutions of centrodes $\sigma_{1}$ and $\sigma_{2}\left(\mathrm{n}_{1}\right.$ and $\left.\mathrm{n}_{2}\right)$ is:
Fig.

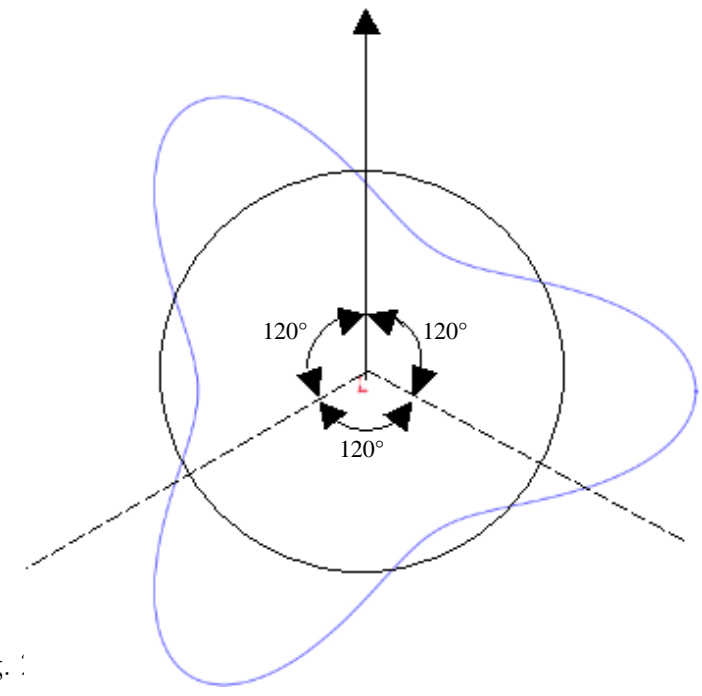

where $n_{1}$ and $n_{2}$ are integer numbers. The center distance between gear drives must be determined as a function of $\mathrm{n}_{1}$ and $\mathrm{n}_{2}$ as following. Represent $\mathrm{r}_{2}\left(\varnothing_{1}\right)$ by the following Eq. 9:

$$
\begin{aligned}
& { }_{2} \varnothing_{1}={ }_{1}\left(\varnothing_{1}\right) \\
& \mathrm{r}() \mathrm{C}-\mathrm{r}
\end{aligned}
$$

The angle of rotation of pinion $\left(\varnothing_{2}\right)$ is:

$$
\begin{gathered}
\varnothing_{2} \varnothing_{1}=\int_{0}^{\varnothing_{1}} \frac{\mathrm{d} \varnothing_{1}}{(\quad)}=\int_{0}^{\varnothing_{12}} \frac{\mathrm{r}_{1}\left(\varnothing_{1}\right)}{()} \mathrm{r} \varnothing_{1}\left(\varnothing_{1}\right) \\
(\quad) \\
\varnothing_{2} \varnothing_{1}=\int_{0}^{\varnothing_{1}} \frac{\mathrm{r}_{1}\left(\varnothing_{1}\right)}{\mathrm{C}-\mathrm{r}_{1}\left(\varnothing_{1}\right)} \mathrm{d} \varnothing_{1} .
\end{gathered}
$$

Finally, from Eq. 8 and 10, we obtain the following Eq. 11 for center distance:

$$
\varnothing_{2}=\frac{2 \pi}{\mathrm{n}_{2}}=\int_{0}^{\frac{2 \pi}{\mathrm{n}_{1}}} \frac{\mathrm{r}_{1}\left(\varnothing_{1}\right)}{\mathrm{C}-\mathrm{r}_{1}\left(\varnothing_{1}\right)} \mathrm{d} \varnothing_{1}
$$

Design of noncircular gear drive with lobes: The term "lobe" refers to gear that has several parts. For example, Fig. 2 shows noncircular gear with three lobes. Here, the design of noncircular gears with lobes is based on the application of conjugated centrodes. Noncircular gear centrode equations are derived by using the following generalized Eq. 12:

$$
r_{1}\left(\varnothing_{1}\right)=\frac{\mathrm{p}}{1-\mathrm{e} \cos \mathrm{m}_{1} \phi_{1}}=\frac{\mathrm{a}\left(1-\mathrm{e}^{2}\right)}{1-\mathrm{e} \cos \mathrm{m}_{1} \phi_{1}}
$$

$$
\frac{\mathrm{T}_{1}}{\mathrm{~T}_{2}}=\frac{\mathrm{n}_{1}}{\mathrm{n}_{2}}
$$


(a)
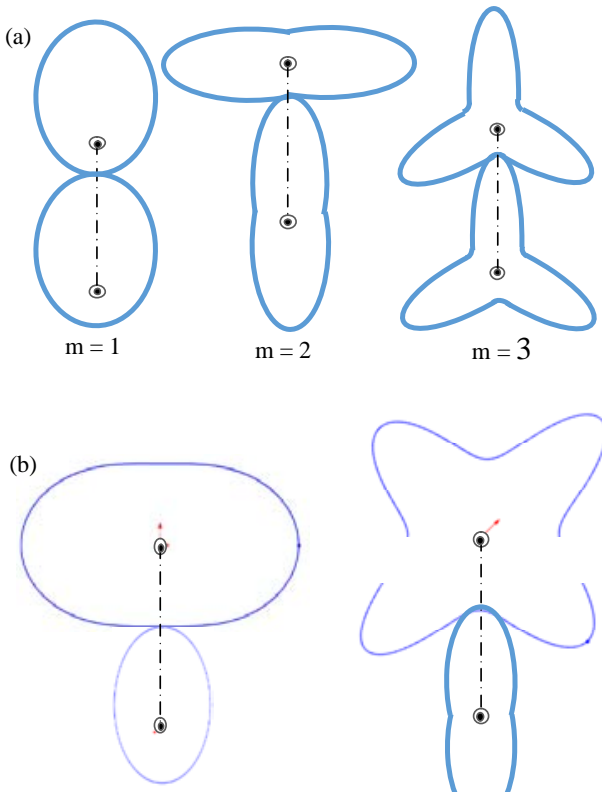

$\mathrm{m}=1$

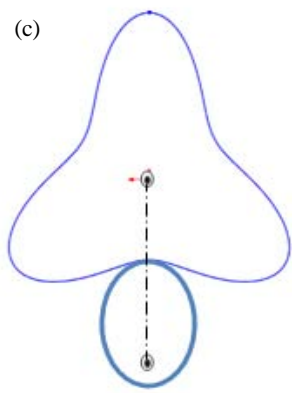

$\mathrm{m}=1$

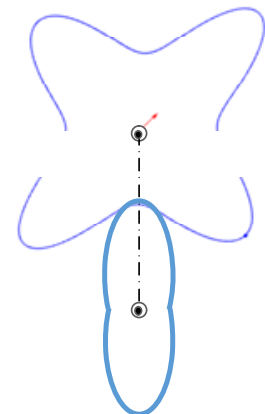

$\mathrm{m}=2$

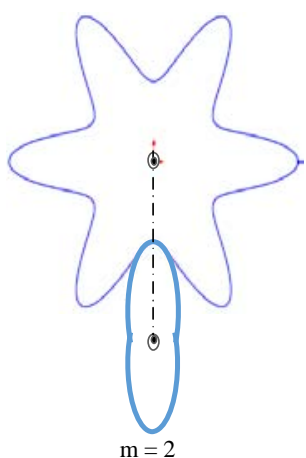

Fig. 3: Noncircular gears centrodes with lobes: a) $\mathrm{n}=$ $1, \mathrm{~m}=1,2,3$; b) $\mathrm{n}=2, \mathrm{~m}=1,2$ and c) $\mathrm{n}=3, \mathrm{~m}=1,2$

$$
\begin{gathered}
\mathrm{r}_{2}\left(\varnothing_{1}\right)=\mathrm{C}-\mathrm{r}_{1}\left(\varnothing_{1}\right) \\
\tan \frac{\mathrm{m}_{2} \varnothing_{2}}{2}=\frac{\sqrt{1+\left(1-\mathrm{e}^{2}\right)\left(\mathrm{n}^{2}-1\right)}+\mathrm{e}}{\mathrm{n}(1-\mathrm{e})} \tan \frac{\mathrm{m}_{1} \varnothing_{1}}{2}
\end{gathered}
$$

where, $\mathrm{m}_{1}$ and $\mathrm{m}_{2}$ are lobes number for gear 1 and 2 , respectively and $\mathrm{n}=\mathrm{m}_{2} / \mathrm{m}_{1}$ is the ratio of revolution numbers of gears 2 and 1 . Figure 3 illustrates some examples of noncircular gear centrodes with different lobes.

Generation of non-circular gears by grinding worm: This method of generation, also, known as a hob is useful from

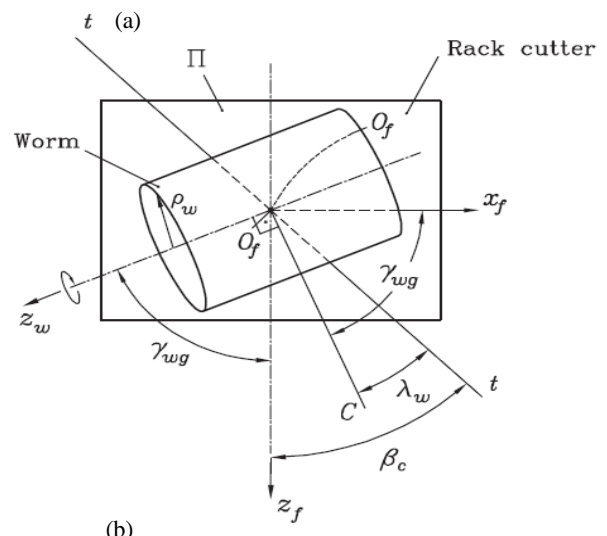

(b)

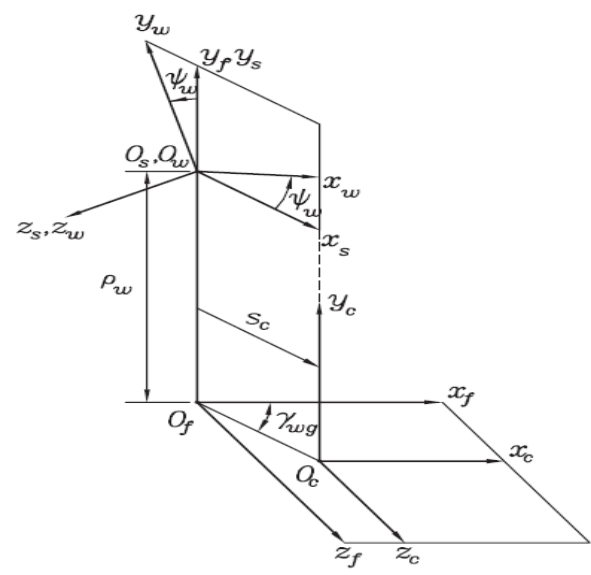

Fig. 4: Generation by hob: a) Position of worm on rack cutter and b) Used coordinate systems

the view point of improving productivity and reliability of gears generated. The surface of the worm thread $\Sigma_{\mathrm{w}}$ is in imaginary meshing with surface of rack-cutter tooth. This meshing condition allows to determine the worm-thread surface. The procedure is as following: Litvin et al. (2009). Shafts of worm and gear are at crossing angle $\gamma_{\mathrm{wg}}$ which is given as (Fig. 4, taking the helix angle $\beta_{c}=0$ for spur gear):

$$
\gamma_{\mathrm{wg}}=\frac{\pi}{2}-\lambda_{\mathrm{w}}
$$

where, $\lambda_{\mathrm{w}}$ is the lead angle of the worm. Consider fixed coordinate systems $\mathrm{S}_{\mathrm{s}}$ and $\mathrm{S}_{\mathrm{f}}$ are define the motion of worm and rack cutter tooth surfaces, respectively. While the movable coordinate system $\mathrm{S}_{\mathrm{w}}$ and $\mathrm{S}_{\mathrm{c}}$ are rigidly connected to surfaces $\Sigma_{\mathrm{w}}$ and $\Sigma_{\mathrm{c}}$, respectively as shown in Fig. 4b.

Rack-cutter tooth surface $\Sigma_{c}$ performs the following motions: translational motion $\mathrm{S}_{\mathrm{c}}$ along the straight line $\mathrm{O}_{\mathrm{f}} \mathrm{C}$ in coordinate systems $\mathrm{S}_{\mathrm{c}}$ as shown in Fig. 4b. This line makes angle $\gamma_{\mathrm{wg}}$ with $\mathrm{x}_{\mathrm{f}}$-axis. Rotational motion about $z_{s}$ axis at an angle $\psi_{w}$ that is: 

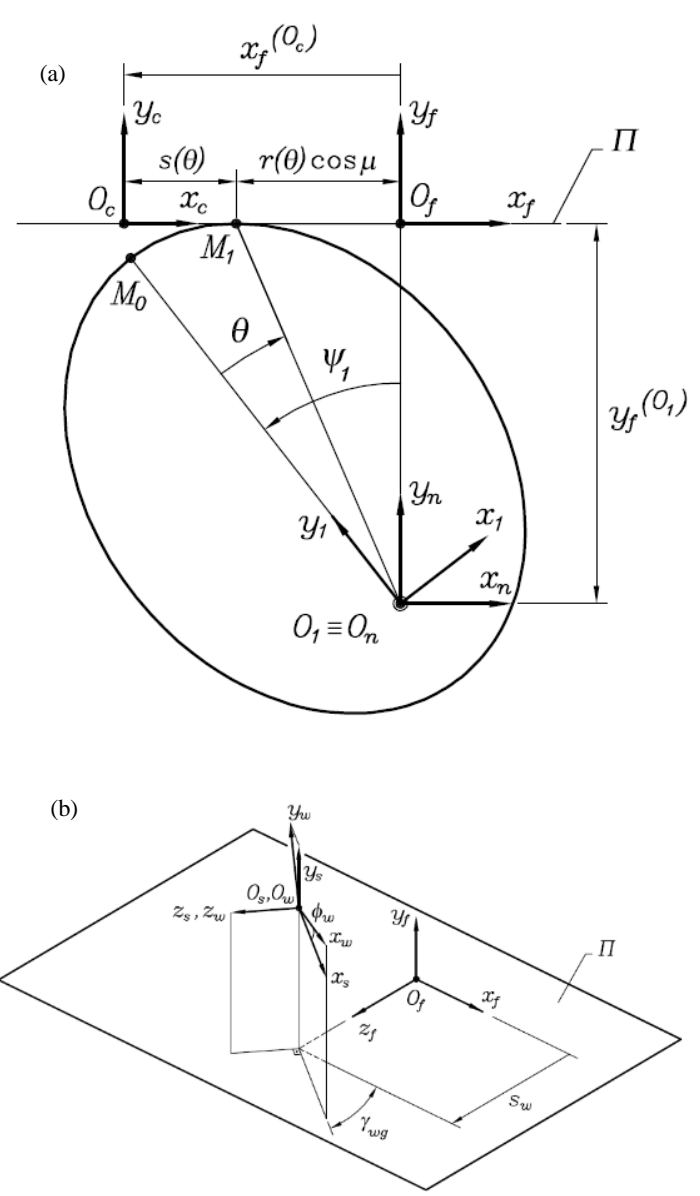

Fig. 5: Coordinate systems for noncircular gear generation by hob: a) Elliptical gear and b) Worm

$$
\psi_{\mathrm{w}}=\frac{\mathrm{S}_{\mathrm{c}}}{\rho_{\mathrm{w}}}
$$

where, $\rho_{w}$ is the grinding worm pitch radius. Surface of the worm thread $\Sigma_{\mathrm{w}}$ can be determined by both vector equation of surface $\Sigma_{\mathrm{w}}$ and meshing equation as following:

$$
\begin{gathered}
\mathrm{r}_{\mathrm{w}}\left(\mathrm{u}_{\mathrm{c}}, 1_{\mathrm{c}}, \psi_{\mathrm{w}}\right)=\mathrm{M}_{\mathrm{wc}}\left(\psi_{\mathrm{w}}\right) \mathrm{r}_{\mathrm{c}}\left(\mathrm{u}_{\mathrm{c}}, 1_{\mathrm{c}}\right) \\
\mathrm{f}_{\mathrm{rc}}\left(\mathrm{u}_{\mathrm{c}}, 1_{\mathrm{c}}, \psi_{\mathrm{w}}\right)=\left(\frac{\partial \mathrm{r}_{\mathrm{c}}}{\partial \mathrm{u}_{\mathrm{c}}} \times \frac{\partial \mathrm{r}_{\mathrm{c}}}{\partial \mathrm{l}_{\mathrm{c}}}\right) \cdot \frac{\partial \mathrm{r}_{\mathrm{c}}}{\partial \psi_{\mathrm{w}}}=0
\end{gathered}
$$

where, $\psi_{\mathrm{w}}$ is the generalized meshing parameter and $\mathrm{M}_{\mathrm{wc}}$ is the coordinate transformation matrix from $\mathrm{S}_{c}$ to $\mathrm{S}_{\mathrm{w}}$. Equation 18 and 19 give the worm thread surface $\Sigma$... that we will refer to it $\mathrm{R}_{\mathrm{w}}\left(\mathrm{u}_{\mathrm{c}}, 1_{\mathrm{c}}, \psi_{\mathrm{w}}\right)$ worm thread surface $\Sigma_{\mathrm{w}}$ is used to derive the elliptical gear surface $\Sigma_{1}$ considering the following (Fig. 5). Consider a fixed coordinate system
$\mathrm{S}_{\mathrm{f}}$ for defining the motions of the coordinate systems $\mathrm{S}_{1}$ and $\mathrm{S}_{\mathrm{w}}$ that are rigidly connected to the gear tooth and worm thread surfaces.

Worm thread surface $\Sigma_{\mathrm{w}}$ performs two motions: translational motion $\left(\mathrm{S}_{\mathrm{w}}\right)$ parallel to gear axis in $\mathrm{z}_{\mathrm{f}}$ axis and rotational motion at an angle $\phi_{\mathrm{w}}$ about $\mathrm{z}_{\mathrm{w}}$ axis. Knowing that $\mathrm{S}_{\mathrm{s}}$ coordinate system is translated with coordinate system $\mathrm{S}_{\mathrm{w}}$. Translation and rotation of the worm and the gear are accompanied together such that the gear translation is along $\mathrm{y}_{\mathrm{f}}$ axis and defined by position $\mathrm{y}_{\mathrm{f}}^{(01)}$ while its rotation about $z_{1}$ axis at an angle $\psi_{1}$. Thus:

$$
\begin{gathered}
y_{\mathrm{f}}^{\left(0_{1}\right)}(\theta)=-r(\theta) \sin \mu \\
\psi_{1}(\theta)=\theta+\mu-\frac{\pi}{2}
\end{gathered}
$$

We tend to determine the following function:

$$
\mathrm{g}\left(\phi_{\mathrm{w}}, \mathrm{S}_{\mathrm{w}}, \theta\right)=0
$$

To determine the worm-thread surface in coordinate system $\mathrm{S}_{1}$, coordinate transformation from $\mathrm{S}_{\mathrm{w}}$ to $\mathrm{S}_{1}$ is used as following:

$$
\mathrm{r}_{1}\left(\mathrm{u}_{\mathrm{c}}, 1_{\mathrm{c}}, \psi_{\mathrm{w}}, \phi_{\mathrm{w}}, \mathrm{S}_{\mathrm{w}}\right)=\mathrm{M}_{1 \mathrm{w}}\left(\phi_{\mathrm{w}}, \mathrm{S}_{\mathrm{w}}\right) \mathrm{R}_{\mathrm{w}}\left(\mathrm{u}_{\mathrm{c}}, 1_{\mathrm{c}}, \psi_{\mathrm{w}}\right)
$$

where $\mathrm{M}_{1 \mathrm{w}}$ is the matrix of coordinate transformation from $S_{w}$ to $S_{1}$. Since, $M_{1 w}$ is a function of two independent parameters $\left(\phi_{\mathrm{w}}\right.$ and $\left.\mathrm{S}_{\mathrm{w}}\right)$, the generation is a double enveloping process. The matrix $\mathrm{M}_{1 \mathrm{w}}$ is:

$$
\begin{gathered}
\mathrm{M}_{1 \mathrm{w}}\left(\phi_{\mathrm{w}}, \mathrm{S}_{\mathrm{w}}\right)=\mathrm{M}_{1 \mathrm{f}}\left(\phi_{\mathrm{w}}, \mathrm{S}_{\mathrm{w}}\right) \mathrm{M}_{\mathrm{fs}}\left(\mathrm{S}_{\mathrm{w}}\right) \mathrm{M}_{\mathrm{sw}}\left(\phi_{\mathrm{w}}\right) \\
\left(\phi_{\mathrm{w}}, \mathrm{S}_{\mathrm{w}}\right)=\left[\begin{array}{cccc}
\cos \psi_{1} & \sin \psi_{1} & 0 & -\mathrm{y}_{\mathrm{f}}^{\left(0_{1}\right)} \sin \psi_{1} \\
-\sin \psi_{1} & \cos \psi_{1} & 0 & -\mathrm{y}_{\mathrm{f}}^{\left(0_{1}\right)} \cos \psi_{1} \\
0 & 0 & 1 & 0 \\
0 & 0 & 0 & 1
\end{array}\right] \\
\mathrm{M}_{\mathrm{fs}}\left(\mathrm{S}_{\mathrm{w}}\right)=\begin{array}{ccccl}
\cos \gamma_{\mathrm{gw}} & 0 & -\sin \gamma_{\mathrm{wg}} & 0 \\
0 & 1 & 0 & \rho_{\mathrm{w}} \\
\sin \gamma_{\mathrm{wg}} & 0 & \cos \gamma_{\mathrm{wg}} & \mathrm{S}_{\mathrm{w}} \\
0 & 0 & 0 & 1 \\
& & & & \\
\cos \phi_{\mathrm{w}} & -\sin \phi_{\mathrm{w}} & 0 & 0 \\
\sin \phi_{\mathrm{w}} & \cos \phi_{\mathrm{w}} & 0 & 0 \\
0 & & 0 & 1 & 0 \\
0 & & 0 & 0 & 1
\end{array}
\end{gathered}
$$



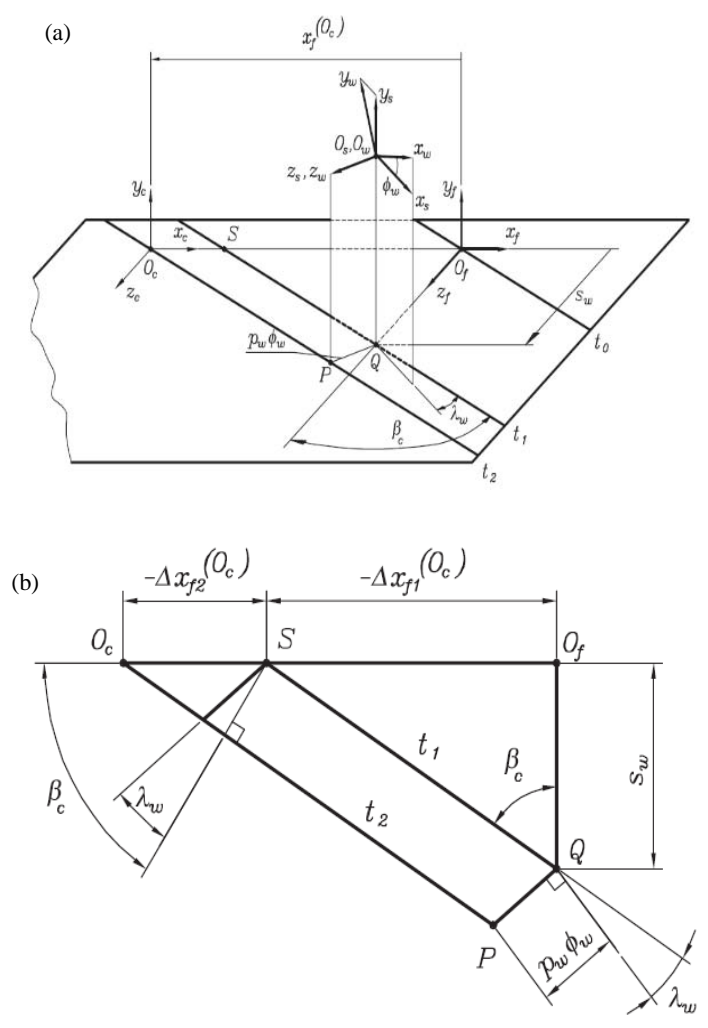

Fig. 6: Determination of function $g\left(\phi_{\mathrm{w}}, \mathrm{s}_{\mathrm{w}}, \theta\right)=0$

Since, the generation of surface $\Sigma_{1}$ is a process of double enveloping, there are two meshing equations:

$$
\begin{aligned}
& f_{1}^{(w 11)}\left(u_{c}, 1_{c}, \psi_{w}, \phi_{w}, S_{w}\right)=0 \\
& f_{2}^{(w 1)}\left(u_{c}, 1_{c}, \psi_{w}, \phi_{w}, S_{w}\right)=0
\end{aligned}
$$

Surface $\Sigma_{1}$ can be determined by simultaneous consideration of Eqs. 23, 28 and 29. Function $\mathrm{g}\left(\phi_{\mathrm{w}}\right.$, $\mathrm{S}_{\mathrm{w},} \theta$ ) $=0$ can be derived as following (Fig. 6): Consider an imaginary rack cutter in simultaneous meshing with the worm and gear surfaces. Coordinate systems $\mathrm{S}_{\mathrm{f}}$ and $\mathrm{S}_{\mathrm{C}}$ are coincident at the initial position. And the surfaces $\Sigma_{w}, \Sigma_{1}$ and $\Sigma_{\mathrm{C}}$ have a common tangent line $\mathrm{t}-\mathrm{t}$ at position $\mathrm{t}_{\mathrm{b}}$.

The common tangent line $\mathrm{t}-\mathrm{t}$ will move to position $\mathrm{t}_{2}$ due to both translational motion $\mathrm{S}_{\mathrm{w}}$ and rotational motion $\phi_{\mathrm{w}}$ of the worm. The system $\mathrm{S}_{\mathrm{C}}$ will move by $\mathrm{x}_{\mathrm{f}}^{(\mathrm{oc})}$. The translational motion $\mathrm{S}_{\mathrm{w}}$ cause a displacement of $\Delta \mathrm{x}^{(0)}{ }_{\mathrm{f}}$ defined by position $t_{0}$ and $t_{1}$. While rotational motion $\phi_{w}$ cause a displacement of $\Delta \mathrm{x}_{{ }_{2}}^{(0 \mathrm{co})}$ defined by position $\mathrm{t}_{1}$ and $\mathrm{t}_{2}$. The total displacement is the sum of these two displacements:

$$
\Delta \mathrm{x}_{\mathrm{f}}^{\left(\mathrm{O}_{\mathrm{c}}\right)}=\Delta \mathrm{x}_{\mathrm{f} 1}^{\left(\mathrm{O}_{1}\right)}+\Delta \mathrm{x}_{\mathrm{f} 2}^{\left(\mathrm{O}_{2}\right)}
$$

$$
\begin{aligned}
&-\Delta \mathrm{x}_{\mathrm{f} 1}^{\left(\mathrm{O}_{\mathrm{c}}\right)}=\overline{\mathrm{O}_{\mathrm{f}} \mathrm{S}}=\tan \beta_{\mathrm{C}} \mathrm{S}_{\mathrm{w}}=0 \\
&-\Delta \mathrm{x}_{\mathrm{f} 2}^{\left(\mathrm{O}_{\mathrm{c}}\right)}=\overline{\mathrm{SO}}=\frac{\mathrm{p}_{\mathrm{w}} \cos \lambda_{\mathrm{w}}}{\cos \beta_{\mathrm{C}}} \phi_{\mathrm{w}}
\end{aligned}
$$

where, $p_{w}$ is the worm pitch. Finally, the function $\mathrm{g}\left(\phi_{\mathrm{w}}, \mathrm{S}_{\mathrm{w}}, \theta\right)=0$ is obtained as following:

$$
\mathrm{g}\left(\phi_{\mathrm{w}}, \mathrm{S}_{\mathrm{w}}, \theta\right)=\mathrm{x}_{\mathrm{f}}^{\left(\mathrm{o}_{\mathrm{c}}\right)}(\theta)+\mathrm{p}_{\mathrm{w}} \cos \lambda_{\mathrm{w}} \phi_{\mathrm{w}}=0
$$

The last step in this method is the derivation of meshing equations as following. From Eqs. 23 and 24, the position vector $r_{1}$ can be written as:

$$
\begin{aligned}
& \mathrm{r}_{1}\left(\mathrm{u}_{\mathrm{c}}, 1_{\mathrm{c}}, \psi_{\mathrm{w}}, \phi_{\mathrm{w}}, \mathrm{S}_{\mathrm{w}}\right)= \\
& {\left[\begin{array}{cccc}
\mathrm{a}_{11} & \mathrm{a}_{12} & \mathrm{a}_{13} & \left(\rho_{\mathrm{w}}-\mathrm{y}_{\mathrm{f}}^{\left(0_{1}\right)}\right) \sin \psi_{1} \\
\mathrm{a}_{21} & \mathrm{a}_{22} & \mathrm{a}_{23} & \left(\rho_{\mathrm{w}}-\mathrm{y}_{\mathrm{f}}^{\left(0_{1}\right)}\right) \sin \psi_{1} \\
\mathrm{a}_{31} & \mathrm{a}_{32} & \mathrm{a}_{33} & \mathrm{~S}_{\mathrm{w}} \\
0 & 0 & 0 & 1
\end{array}\right] \mathrm{R}_{\mathrm{w}}\left(\mathrm{u}_{\mathrm{c}}, 1_{\mathrm{c}}, \psi_{\mathrm{w}}\right)}
\end{aligned}
$$

Where:

$\mathrm{a}_{11}=\cos \psi_{1} \cos \gamma_{\mathrm{wg}} \cos \phi_{\mathrm{w}}+\sin \psi_{1} \sin \phi_{\mathrm{w}}$

$\mathrm{a}_{12}=\cos \psi_{1} \cos \gamma_{\mathrm{wg}} \cos \phi_{\mathrm{w}}+\sin \psi_{1} \sin \phi_{\mathrm{w}}$

$\mathrm{a}_{13}=\cos \psi_{1} \sin \gamma_{\mathrm{wg}}$

$\mathrm{a}_{21}=\cos \psi_{1} \cos \gamma_{\mathrm{wg}} \cos \phi_{\mathrm{w}}+\cos \psi_{1} \sin \phi_{\mathrm{w}}$

$\mathrm{a}_{22}=\sin \psi_{1} \cos \gamma_{\mathrm{wg}} \sin \phi_{\mathrm{w}}+\cos \psi_{1} \cos \phi_{\mathrm{w}}$

$\mathrm{a}_{23}=\sin \psi_{1} \sin \gamma_{\mathrm{wg}}$

$\mathrm{a}_{31}=\sin \gamma_{\mathrm{wg}} \cos \phi_{\mathrm{w}}$

$\mathrm{a}_{32}=\sin \gamma_{\mathrm{wg}} \sin \phi_{\mathrm{w}}$

$\mathrm{a}_{33}=\cos \gamma_{\mathrm{wg}}$

Let, $\rho_{1}\left(\mathrm{u}_{\mathrm{c}}, \mathrm{l}_{\mathrm{c}}, \psi_{\mathrm{w}}, \phi_{\mathrm{w}}, \mathrm{S}_{\mathrm{w}}\right)$ is the position vector $\mathrm{r}_{1}\left(\mathrm{u}_{\mathrm{c}}, 1_{\mathrm{c}}, \psi_{\mathrm{w},} \phi_{\mathrm{w},} \mathrm{S}_{\mathrm{w}}\right)$ in Cartesian coordinates that can be written as:

$$
\begin{aligned}
& \rho_{1}\left(\mathrm{u}_{\mathrm{c}}, 1_{\mathrm{c}}, \psi_{\mathrm{w}}, \phi_{\mathrm{w}}, \mathrm{S}_{\mathrm{w}}\right)=\mathrm{L}_{1 \mathrm{w}}\left(\phi_{\mathrm{w}}, \mathrm{S}_{\mathrm{w}}\right) \rho_{\mathrm{w}}\left(\mathrm{u}_{\mathrm{c}}, 1_{\mathrm{c}}, \psi_{\mathrm{w}}\right)+ \\
& \mathrm{R}=\left[\begin{array}{ccc}
\mathrm{a}_{11} & \mathrm{a}_{12} & \mathrm{a}_{13} \\
\mathrm{a}_{21} & \mathrm{a}_{22} & \mathrm{a}_{23} \\
\mathrm{a}_{31} & \mathrm{a}_{32} & \mathrm{a}_{33}
\end{array}\right] \rho_{\mathrm{w}}\left(\mathrm{u}_{\mathrm{c}}, 1_{\mathrm{c}}, \psi_{\mathrm{w}}\right)+ \\
& \left(\rho_{\mathrm{w}}-\mathrm{y}_{\mathrm{f}}^{\left(0_{1}\right)}\right) \sin \psi_{1}\left(\rho_{\mathrm{w}}-\mathrm{y}_{\mathrm{f}}^{\left(0_{1}\right)}\right) \cos \psi_{1} \mathrm{~S}_{\mathrm{w}}
\end{aligned}
$$

where, $L_{1 w}$ is $3 \times 3$ matrix results by eliminating last raw and last column of $\mathrm{M}_{1 \mathrm{w}}$ matrix or results as Eq. (24) from the relation $\mathrm{L}_{1 \mathrm{w}}=\mathrm{L}_{1 \mathrm{f}} \mathrm{L}_{\mathrm{fs}} \mathrm{L}_{\mathrm{sw}}$ and:

$$
\mathrm{R}=\mid\left(\left.\begin{array}{lll}
\left.\rho_{\mathrm{w}}-\mathrm{y}_{\mathrm{f}}^{\left(0_{1}\right)}\right) \sin \psi_{1} & \left.\rho_{\mathrm{w}}-\mathrm{y}_{\mathrm{f}}^{\left(0_{1}\right)}\right) \cos \psi_{1} \quad \mathrm{~S}_{\mathrm{w}}
\end{array}\right|^{\mathrm{T}}\right.
$$

To find the first meshing equation $\mathrm{f}^{(\mathrm{w} 1)}=0$, consider $\mathrm{S}_{\mathrm{w}}=0$ (constant). Then the worm thread surface velocity relative to gear tooth surface is: 
Where:

$$
\mathrm{V}_{1, \Delta \mathrm{S}_{\mathrm{w}}=0}^{(\mathrm{w} 1)}=\dot{\rho}_{1}=\dot{\mathrm{L}}_{1 \mathrm{w}} \rho_{\mathrm{w}}+\dot{\mathrm{R}}
$$

$$
\begin{gathered}
\dot{\mathrm{R}}=\left[\begin{array}{c}
\operatorname{Cos} \psi_{1}\left(\mathrm{p}_{\mathrm{w}}-\mathrm{y}_{\mathrm{f}}^{\left(\mathrm{O}_{1}\right)}\right) \dot{\psi}_{1}-\dot{\mathrm{y}}_{\mathrm{f}}^{\left(\mathrm{O}_{1}\right)} \sin \psi_{1} \\
-\sin \psi_{1}\left(\mathrm{p}_{\mathrm{w}}-\mathrm{y}_{\mathrm{f}}^{\left(\mathrm{O}_{1}\right)}\right) \dot{\psi}_{1}-\dot{\mathrm{y}}_{\mathrm{f}}^{\left(\mathrm{O}_{1}\right)} \sin \psi_{1}
\end{array}\right] \\
\dot{\mathrm{L}}_{1 \mathrm{w}}=\dot{\mathrm{L}}_{1 \mathrm{f}} \mathrm{L}_{\mathrm{fs}} \mathrm{L}_{\mathrm{sw}}+\mathrm{L}_{1 \mathrm{f}} \mathrm{L}_{\mathrm{fs}} \dot{\mathrm{L}}_{\mathrm{sw}} \\
\dot{\mathrm{L}}_{1 \mathrm{f}}=\left[\begin{array}{ccc}
-\sin \psi_{1} & -\cos \psi_{1} & 0 \\
-\cos \psi_{1} & -\sin \psi_{1} & 0 \\
0 & 0 & 0
\end{array}\right] \dot{\psi}_{1} \\
\dot{\mathrm{L}}_{\mathrm{sw}}=\left[\begin{array}{ccc}
-\sin \phi_{\mathrm{w}} & -\cos \phi_{\mathrm{w}} & 0 \\
\cos \phi_{\mathrm{w}} & -\sin \phi_{\mathrm{w}} & 0 \\
0 & 0 & 0
\end{array}\right] \dot{\phi}_{\mathrm{w}} \\
\dot{\phi}_{\mathrm{w}}=\frac{-\cos \beta \mathrm{c}}{\mathrm{p}_{\mathrm{w}} \cos \lambda_{\mathrm{w}}} \dot{\mathrm{x}}_{\mathrm{f}}^{\left(\mathrm{O}_{\mathrm{s}}\right)} \\
\mathrm{n}_{1}=\mathrm{L}_{\mathrm{sw}} \mathrm{n}_{\mathrm{w}}
\end{gathered}
$$

$\mathrm{n}_{\mathrm{w}}$ is the unit normal to worm thread surface. Thus:

$$
\mathrm{f}_{1}^{(\mathrm{w} 1)}=\mathrm{n}_{1} \cdot V_{1, \Delta_{\mathrm{w}}=0}^{(\mathrm{w} 1)}=0
$$

To find the second meshing equation $\mathrm{f}_{2}^{(\mathrm{w} 1)}=0$, consider $\phi_{\mathrm{w}}=\mathrm{c}$ (constant). In this case, the worm thread surface velocity relative to gear tooth surface is:

$$
\begin{gathered}
\mathrm{V}_{1, \Delta \phi_{w}=0}^{(\mathrm{w} 1)}=\dot{\mathrm{p}}_{1}=\dot{\mathrm{L}}_{1 \mathrm{w}} \mathrm{P}_{\mathrm{w}}+\dot{\mathrm{R}} \\
\dot{\mathrm{R}}=\left[\begin{array}{c}
\cos \psi_{1}\left(\mathrm{p}_{\mathrm{w}}-\mathrm{y}_{\mathrm{f}}^{\left(\mathrm{O}_{1}\right)}\right) \dot{\Psi}_{1}-\dot{\mathrm{y}}_{\mathrm{f}}^{\left(\mathrm{O}_{1}\right)} \sin \psi_{1} \\
-\sin \psi_{1}\left(\mathrm{p}_{\mathrm{w}}-\mathrm{y}_{\mathrm{f}}^{\left(\mathrm{O}_{1}\right)}\right) \dot{\psi}_{1}-\dot{\mathrm{y}}_{\mathrm{f}}^{\left(\mathrm{O}_{1}\right)} \cos \psi_{1} \\
\dot{\mathrm{s}}_{\mathrm{w}}
\end{array}\right] \\
\dot{\mathrm{S}}_{\mathrm{w}}=\frac{-1}{\tan \beta \mathrm{c}} \dot{\mathrm{x}}_{\mathrm{f}}^{\left(\mathrm{O}_{\mathrm{c}}\right)} \\
\dot{\mathrm{L}}_{1 \mathrm{w}}=\dot{\mathrm{L}}_{1 \mathrm{f}} \mathrm{L}_{\mathrm{fs}} \mathrm{L}_{\mathrm{sw}}
\end{gathered}
$$

$\dot{L}_{1 \mathrm{f}}$ is exactly the same as Eq. 39. Thus:

$$
\mathrm{f}_{2}^{(\mathrm{w} 1)}=\mathrm{n}_{1} \cdot V_{1, \Delta \phi_{w}=0}^{(\mathrm{w} 1)}=0
$$

Knowing that $\dot{\mathrm{x}}_{\mathrm{f}}^{\left(\mathrm{O}_{\mathrm{c}}\right)}, \dot{\mathrm{y}}_{\mathrm{f}}^{\left(\mathrm{O}_{1}\right)}$ and $\dot{\psi}_{1}$ are given as:

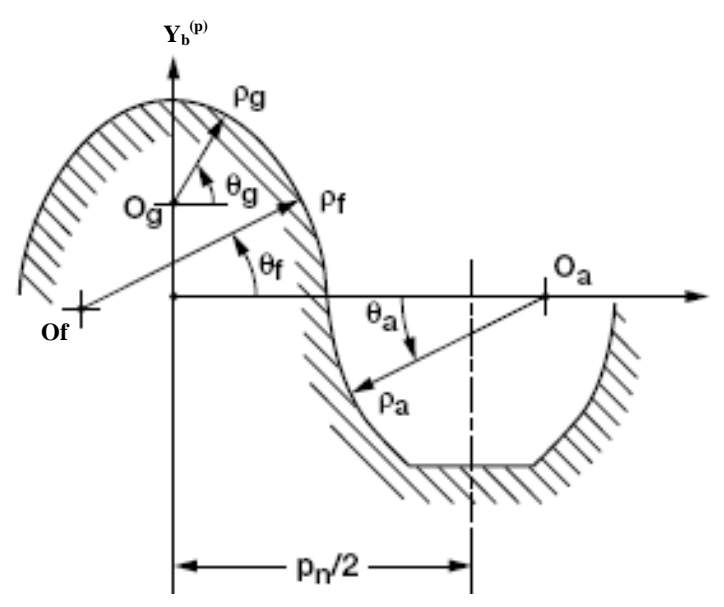

Fig. 7: Normal section of rack-cutter for double circular arc tooth profile

$$
\begin{aligned}
& \dot{x}_{f}^{\left(O_{c}\right)}=\frac{d x_{f}^{\left(O_{c}\right)}}{d \theta} \frac{d \theta}{d t}, \dot{y}_{f}^{\left(O_{1}\right)}=\frac{d y_{f}^{\left(O_{1}\right)}}{d \theta} \frac{d \theta}{d t} \\
& \dot{\psi}_{1}=\frac{d \psi_{1}}{d \theta} \frac{d \theta}{d t}
\end{aligned}
$$

And the helix angle $\beta_{\mathrm{c}}$ in all equations is zero for spur gear.

Double circular arc tooth profile: The rack cutter has a normal section as shown in Fig. 7. The rack cutter tooth profile is symmetric about $y_{b}^{(p)}$-axis. The tooth of the rack cutter consists of three circular arcs in each side and can be represented in coordinate system $s_{b}^{(p)}$ by the following Eq. 49 (Liu and Chen, 2008):

$$
\mathrm{r}_{b}^{(p)}=\left[\begin{array}{c}
\mathrm{x}_{b}^{(p)} \\
y_{b}^{(p)} \\
z_{b}^{(p)}
\end{array}\right]=\left[\begin{array}{c}
\rho_{p} \cos \theta_{p}+x_{o p} \\
\rho_{p} \sin \theta_{p}+y_{o p} \\
0
\end{array}\right]
$$

where, $\left(\mathrm{x}_{\mathrm{op}}, \mathrm{y}_{\mathrm{op}}\right)$ are the coordinates of arcs centers, $\rho_{\mathrm{p}}$ is the arcs radius, $\theta_{\mathrm{p}}$ is the angle (variable parameter) and the subscribed $\rho=a, f, g$. Knowing that the working surface of the tooth is generated by $\mathrm{p}_{\mathrm{a}}$ and $\mathrm{p}_{\mathrm{f}}$ while $\mathrm{p}_{\mathrm{g}}$ generates the fillet. Equation 49 represents the position vector of rack cutter tooth of double circular arc type.

This rack cutter can be used to generate any noncircular gear using various generation processes.

\section{RESULTS AND DISCUSSION}

A computer program has been built using SOLIDWORK 2016 to generate noncircular gears of any centrode shape (different values of major radius, 

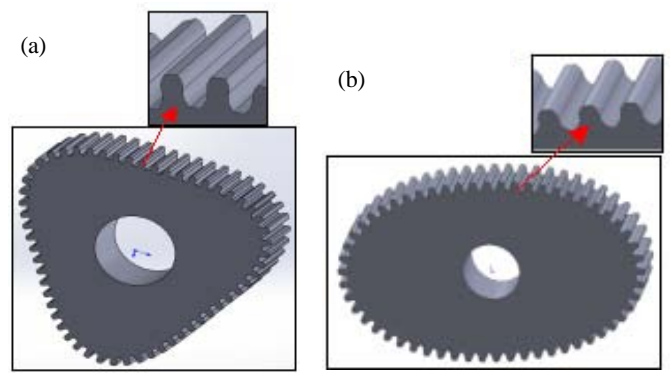

(c)

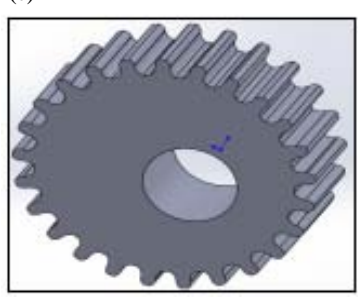

Fig. 8: Samples of generated non-circular gears with double circular arc tooth profile of $20^{\circ}$ pressure angle using SOLIDWORK program: a) 3-lobes gear with $\mathrm{m}_{0}=1 \mathrm{~mm}$ and teeth number $\mathrm{N}=57$; b) 2-lobes (Oval) gear with $\mathrm{m}_{0}=1 \mathrm{~mm}$ and $\mathrm{N}=56$ and c) Elliptical gear with $\mathrm{m}_{0}=3 \mathrm{~mm}$ and $\mathrm{N}=25$
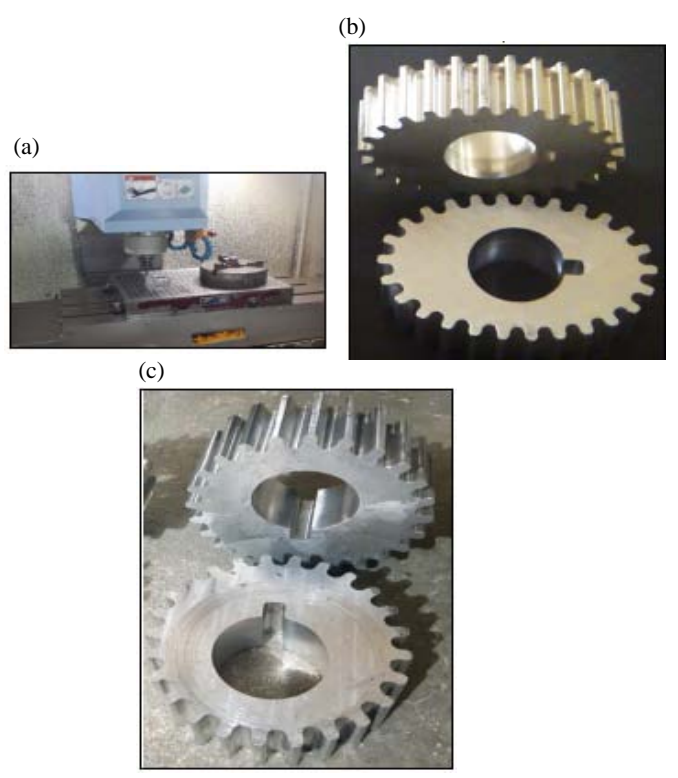

Fig. 9: a) Non-circular gear generation in CNC Machine; b) 2-lobes (Oval) aluminum gear with $\mathrm{m}_{0}=3 \mathrm{~mm}$ and teeth number $\mathrm{N}=26$ and c) Elliptical aluminum gear with $\mathrm{m}_{0}=3 \mathrm{~mm}$ and $\mathrm{N}=25$. Pressure angle $=$ $20^{\circ}$, face width $=30 \mathrm{~mm}$

eccentricity and lobes number $\mathrm{m}$ or $\mathrm{n}$ or both) with double circular arc teeth profile for different gear design parameters (module, pressure angle, teeth number and face width) using the mathematical relations derived in this study for centrode representation and generation process. Also, the resulted computerized models of noncircular gears can be coupled directly to $\mathrm{CNC}$ machine to generate actual samples of noncircular gears or use these models in finite element analysis. Figure 8 shows number of computerized generated samples with different lobes (centrode shape) of double circular arc teeth profile in SOLIDWORK. While, Fig. 9 shows actual samples of noncircular gears (oval gear and elliptical gear with eccentricity of 0.2 and minimum radius of $36 \mathrm{~mm}$ ) generated by $\mathrm{CNC}$ machine using aluminum material with $3 \mathrm{~mm}$ module, $30 \mathrm{~mm}$ face width and $20^{\circ}$ pressure angle. The resulted samples are very accurate in meshing process and pitch curves of driver and driven gears are match together without clearance or backlash.

\section{CONCLUSION}

The design and generation of noncircular gears are more complex than circular gears due to the continuous change in pitch curve. Knowing that the pitch curve (centrode shape) specify the type of noncircular gear such as elliptical gear, oval gear and other types. Therefore, a mathematical equation of centrode shape derived in this study can be used to represent any shape of noncircular gear with any lobe number. In addition, the derived double circular arc tooth profile equations can be used to represent the circular arc teeth with any module and pressure angle. The resulted mathematical equations for these gears are computerized successfully in SOLIDWORK program to represent any type of noncircular gear with double circular arc teeth. This enables to manufacture the noncircular gears by $\mathrm{CNC}$ machine or any computerized machine through direct coupling between SOLIDWORK program and these machines. Also, it helps to analyze the static and dynamic behavior of these gears using SOLIDWORK program itself or using any other program that can be coupled with solidwork such as ANSYS program.

\section{REFERENCES}

Bair, B.W., 2002. Computerized tooth profile generation of elliptical gears manufactured by shaper cutters. J. Mater. Process. Technol., 122: 139-147.

Cunningham, F.W., 1959. Designing and using noncircular gears to generate mathematical functions. Mach. Des., 1: 161-164.

Danieli, G.A., 2000. Analytical description of meshing of constant pressure angle teeth profiles on a variable radius gear and its applications. J. Mech. Des., 122: 123-129. 
Han, J., D.Z. Li, T. Gao and L. Xia, 2015. Research on obtaining of tooth profile of non-circular gear based on virtual slotting. Proceedings of the 14th IFToMM World Congress, November 6, 2015, IFToMM, Taipei, Taiwan, pp: 229-233.

Kuczewski, M., 1988. Designing elliptical gears. Mach. Des., 60: 116-118.

Li, J., X. Wu and S. Mao, 2007. Numerical computing method of noncircular gear tooth profiles generated by shaper cutters. Intl. J. Adv. Manuf. Technol., 33: 1098-1105.

Litvin, F.L. and J. Lu, 1997. New Methods for Improved Double Circular-Arc Helical Gears. National Aeronautics and Space Administration, Washington, USA., Pages: 60.

Litvin, F.L., A. Fuentes, I.G. Perez, K. Hayasaka and K. Hayasaka, 2009. Noncircular Gears: Design and Generation. Cambridge University Press, Cambridge, UK., ISBN:9780511605215, Pages: 204.

Litvin, F.L., I. Gonzalez-Perez, K. Yukishima, A. Fuentes and K. Hayasaka, 2007. Generation of planar and helical elliptical gears by application of rack-cutter, hob and shaper. Comput. Methods Appl. Mech. Eng., 196: 4321-4336.

Liu, J.Y. and Y.C. Chen, 2008. A design for the pitch curve of noncircular gears with function generation. Proceedings of the International MultiConference on Engineers and Computer Scientists (IMECS 2008) Vol. 2, March 19-21, 2008, IAENG, Hong Kong, pp: $1-6$.
Marius, V. and A. Laurentia, 2010. Technologies for non-circular gear generation and manufacture. Techolol. Mach. Build., 1: 167-172.

Mundo, D. and G.A. Danieli, 2004. Use of non-circular gears in pressing machine driving systems. Mech. Mechatron., 1: 1-5.

Riaza, H.F.Q., S.C. Foix and L.J. Nebot, 2007. The synthesis of an N-lobe noncircular gear susing Bezier and B-Spline nonparametric curves in the design of its displacement law. J. Mech. Des., 129: 981-985.

Vanegas-Useche, L.V., M.M. Abdel-Wahab and G.A. Parker, 2016. A new noncircular gear pair to reduce shaft accelerations: A comparison with sinusoidal and elliptical gears. DYNA., 83: 219-227.

Vasie, M. and L. Andrei, 2011. Noncircular gear design and generation by rack cutter. Technol. Mach. Build., 1: $69-74$.

Zhang, X. and S. Fan, 2018. Study on the pitch curve with minimal rotary inertia for the noncircular gears. J. Mech. Eng. Sci., 232: 2666-2673.

Zheng, F., H. Xinghui, L. Hua, M. Zhang and Z. Weiqinga, 2018. Design and manufacture of new type of non-circular cylindrical gear generated by face-milling method. Mech. Mach. Theory, 122: 326-346. 